\title{
SOLUTIONS OF THE MATRIX INEQUALITIES IN THE MINUS PARTIAL ORDERING AND LÖWNER PARTIAL ORDERING
}

\author{
YONGGE TIAN
}

Abstract. Two matrices $A$ and $B$ of the same size are said to satisfy the minus partial ordering, denoted by $B \leqslant^{-} A$, iff the $\operatorname{rank}$ subtractivity equality $\operatorname{rank}(A-B)=\operatorname{rank}(A)-\operatorname{rank}(B)$ holds; two complex Hermitian matrices $A$ and $B$ of the same size are said to satisfy the Löwner partial ordering, denoted by $B \leqslant{ }^{\mathrm{L}} A$, iff the difference $A-B$ is nonnegative definite. In this note, we establish general solution of the inequality $B X B^{*} \leqslant^{-} A$ induced from the minus partial ordering, and general solution of the inequality $B X B^{*} \leqslant{ }^{\mathrm{L}} A$ induced from the Löwner partial ordering, respectively, where $(\cdot)^{*}$ denotes the conjugate transpose of a complex matrix. As consequences, we give closed-form expressions for the shorted matrices of $A$ relative to the range of $B$ in the minus and Löwner partial orderings, respectively, and show that these two types of shorted matrices in fact are the same.

Mathematics subject classification (2010): 15A03, 15A09, 15A24, 15 B57.

Keywords and phrases: Minus partial ordering, Löwner partial ordering, Hermitian matrix, matrix function, matrix equation, Moore-Penrose inverse, shorted matrix, rank, inertia.

\section{REFERENCES}

[1] W. N. Anderson, JR., Shorted operators, SIAM J. Appl. Math. 20 (1971), 522-525.

[2] W. N. Anderson, JR. AND G. E. Trapp, Shorted operators II, SIAM J. Appl. Math. 28 (1975), 60-71.

[3] H. GolLER, Shorted operators and rank decomposition matrices, Linear Algebra Appl. 81 (1986), 207-236.

[4] J. GRoss, A note on the rank-subtractivity ordering, Linear Algebra Appl. 289 (1999), 151-160.

[5] R. E. HARTwig AND G. P. H. STYAn, On some characterizations of the "star" partial ordering for matrices and rank subtractivity, Linear Algebra Appl. 82 (1986), 145-161.

[6] C. G. Khatri And S. K. Mitra, Hermitian and nonnegative definite solutions of linear matrix equations, SIAM J. Appl. Math. 31 (1976), 579-585.

[7] Y. LIU AND Y. TIAN, Hermitian-type of singular value decomposition for a pair of matrices and its applications, Numer. Linear Algebra Appl., DOI: 10.1002/nla.1825.

[8] G. Mars AGlia AND G. P. H. Styan, Equalities and inequalities for ranks of matrices, Linear and Multilinear Algebra 2 (1974), 269-292.

[9] S. K. Mitra, The minus partial order and the shorted matrix, Linear Algebra Appl. 83 (1986), 1-27.

[10] S. K. Mitra, P. Bhimas ankaram, S. B. Malik, Matrix Partial Orders, Shorted Operators and Applications, World Scientific Publishing, 2010.

[11] S. K. Mitra AND M. L. PURI, Shorted matrices-an extended concept and some applications, Linear Algebra Appl. 42 (1982), 57-79.

[12] R. Penrose, A generalized inverse for matrices, Proc. Cambridge Philos. Soc. 51 (1955), 406-413.

[13] Y. TIAn, Equalities and inequalities for inertias of Hermitian matrices with applications, Linear Algebra Appl. 433 (2010), 263-296.

[14] Y. TIAN AND Y. LIU, Extremal ranks of some symmetric matrix expressions with applications, SIAM J. Matrix Anal. Appl. 28 (2006), 890-905. 